\title{
Modelo conceitual para avaliação de práticas e estratégias climáticas: resultados de sua aplicação nos setores automotivo e de papel e celulose no Brasil*
}

\author{
Paulo G. Fuchs**
}

T. Diana L. van Aduard de Macedo-Soares***

Giuseppe Russo****

Sumário: 1. Introdução; 2. Estratégia climática; 3. Modelo conceitual proposto; 4. Métodos de pesquisa; 5. Resultados; 6. Análise dos resultados; 7. Conclusão.

Summary: 1. Introduction; 2. Climate strategy; 3. Proposed conceptual model; 4. Research methods; 5. Results; 6. Result analysis; 7. Conclusion.

Palavras-chave: estratégia; estratégia climática; mudanças climáticas; gases de efeito estufa (GEEs); avaliação de estratégias climáticas; melhores práticas climáticas; setor automotivo; setor de papel e celulose.

KEY WORDs: strategy; climate change strategy; climate change; greenhouse gases (GHG); climate change assessment; climatic best practices; automotive industry; pulp \& paper industry.

A alta concentração de gases de efeito estufa está provocando mudanças climáticas com forte impacto, inclusive no ambiente competitivo das empresas. Assim, algumas empresas já estão adotando práticas e estratégias climáticas em função não somente

\footnotetext{
* Artigo recebido em fev. e aceito em jun. 2009.

** M.Sc., engenheiro eletrônico do Banco Nacional de Desenvolvimento Econômico e Social (BNDES). Endereço: Av. República do Chile, 100, s. 1.810 - Centro - CEP 20031-917, Rio de Janeiro, RJ, Brasil. E-mail: solfuchs@globo.com.

*** PhD, professora associada da Pontifícia Universidade Católica do Rio de Janeiro (IAG/PUCRio). Endereço: Av. Marquês de São Vicente, 225 - Gávea - CEP 22453-900, Rio de Janeiro, RJ, Brasil. E-mail: redes@strategy-research.com.br.

**** DSc, professor e pesquisador da Pontifícia Universidade Católica do Rio de Janeiro (IAG/ PUC-Rio). Endereço: Rua Resedá, 10 - Lagoa - CEP 22471-230, Rio de Janeiro, RJ, Brasil. E-mail: giuseppe.russo@globo.com.
} 
das legislações restritivas ao carbono, mas também para assegurarem sua vantagem competitiva. Contudo, há uma escassez de ferramentas gerenciais para avaliar o quanto tais práticas e estratégias são adequadas a esse novo contexto. Este artigo apresenta um modelo conceitual desenvolvido com base em benchmarks (melhores práticas) internacionais, para auxiliar as empresas na avaliação das suas práticas e estratégias climáticas, e mostra como o modelo foi aplicado no Brasil em dois setores representativos de sua economia: o automotivo e o de papel e celulose. Identifica as práticas e estratégias climáticas que precisam ser melhoradas nesses setores, quando comparadas com as internacionais. Na aplicação do modelo, foram testadas cinco hipóteses referentes às principais variáveis do modelo proposto. Para tanto, realizaram-se testes estatísticos: teste $t$-student, para comparação com as práticas internacionais, e teste não paramétrico Kruskal-Wallis, para verificar diferenças entre as médias dos dois setores investigados. Com base nos resultados, são feitas recomendações para futuras pesquisas e para outras empresas preocupadas em adotar práticas e estratégias climáticas eficazes.

\section{Environmental practices and strategies assessmente model: results of its application to the automotive and pulp \& paper sectors in Brazil}

The high concentration of green house gases is causing climate changes that have a strong impact on the competitiveness of firms. Some businesses are adopting environmental practices and strategies not only because of carbon restrictive regulations, but also to ensure their competitive advantage. However, there is a lack of adequate managerial tools to evaluate the effectiveness of these practices and strategies. This article presents a conceptual model based on international benchmarks, developed to help firms assess their environmental practices and strategies. It shows how the model was applied in Brazil in two representative sectors of the its economy: automotive and pulp \& paper sectors. It also identifies the environmental practices and strategies that should be improved by these firms, when compared to international benchmarks. In the scope of the model's application, five hypotheses related to its main variables were tested statistically. The $t$-student test was carried out to compare the firms' practices to international benchmarks, while the non-parametric KruskalWallis test was used to check differences between the averages of the two sectors under investigation. Based on the results, recommendations are made both for future research and for other firms concerned with adopting efficient environmental practices and strategies.

\section{Introdução}

Como é sabido, o atual paradigma de produção, baseado principalmente no consumo de combustíveis fósseis, tem provocado aumentos expressivos das emissões antrópicas de gases de efeito estufa — GEE (Collins, 2006). A alta concentração desses gases na atmosfera aumenta a temperatura média da su- 
perfície da Terra, provocando mudanças climáticas que prejudicam o equilíbrio do clima global (Lis $\varnothing, 2006)$.

A concentração de gás carbônico $\left(\mathrm{CO}_{2}\right)$ e de outros GEEs na atmosfera, que se manteve estável durante milhares de anos, começou a aumentar, substancialmente, a partir do século XIX, após a Revolução Industrial. Esses gases decorrem, principalmente, da queima de combustíveis fósseis, dos processos industriais e das mudanças no uso da terra, como, por exemplo, a derrubada de florestas e as queimadas. Há fortes evidências de que o aumento excessivo dos níveis de $\mathrm{CO}_{2}$ e de outros GEEs na atmosfera não é decorrente de fatores naturais, mas causado pelas atividades humanas. Segundo vários estudos científicos, a concentração de $\mathrm{CO}_{2}$ na atmosfera atingirá o dobro dos níveis pré-industriais até o ano 2065 (IPCC, 2006, 2007).

As mudanças climáticas estão causando forte impacto também no ambiente competitivo empresarial em consequência do estabelecimento de legislações restritivas às emissões de GEE, do aumento dos preços da energia e do interesse da comunidade financeira pelo assunto (Hoffman, 2006).

Nesse contexto, as pressões para que as empresas atuem em harmonia com o meio ambiente têm aumentado significativamente (Hoffman, 2005; Enkvist, Nauclér e Oppenheim, 2008). São exercidas por vários tipos de atores, tais como consumidores, fornecedores, comunidades, organizações não governamentais (ONGs), governos e empregados (Hoffman, 2000). Mais recentemente, um novo grupo de stakeholders começou a exercer pressão: os bancos e as seguradoras (Esty e Winston, 2006; Maynard, 2008). A atuação desse novo grupo é significativa porque, como disseram Esty e Winston (2006:9), "... when the financial services industry, which focuses like a laser on return on investments, starts worrying about the environment, you know something big is happening".

Neste cenário de forte impacto das mudanças climáticas na competitividade das empresas, torna-se fundamental adotar estratégias climáticas que contribuam para assegurar a sustentabilidade dos seus negócios. A pesquisa realizada pela McKinsey Quaterly no final de 2007 evidenciou que quase 2/3 (60\%) dos executivos entrevistados acreditavam que a mudança climática era uma questão de ordem estratégica. No entanto, também revelou que poucos estão efetivamente fazendo alguma coisa neste sentido (Enkvist e Vanthournout, 2008).

Um dos problemas identificados na nossa revisão da literatura é a falta de ferramentas gerenciais apropriadas à avaliação e à formulação de estratégias climáticas. 
Este artigo compartilha os resultados de uma pesquisa que desenvolveu, precisamente um arcabouço conceitual, baseado em estratégias e melhores práticas climáticas, para superar tal lacuna.

O arcabouço conceitual é chamado de Modelo de Estratégias Climáticas (MDEC). Tem a função de auxiliar os gestores na avaliação e eventualmente na formulação de estratégias climáticas empresariais adequadas ao contexto atual de impacto crescente das mudanças climáticas nos resultados dos negócios das empresas, considerando o leque ampliado de stakeholders nesse contexto. O modelo foi aplicado em dois setores industriais no Brasil, o automotivo e o de papel e celulose, como instrumento de avaliação das suas práticas e estratégias climáticas para ilustrar como pode ser utilizado. Pela mesma ocasião, permitiu identificar as práticas e estratégias climáticas adequadas e as que precisam ser melhoradas, nesses setores, quando comparadas com as dos benchmarks (padrões de referência) internacionais. Cabe notar que na pesquisa o modelo ainda não foi aplicado como instrumento de formulação ou desenvolvimento de estratégias climáticas; por isso o artigo limita-se a apresentar resultados pertinentes ao modelo como instrumento de avaliação.

$\mathrm{O}$ artigo é dividido em seis partes, além desta introdução. Na próxima parte define-se o conceito de estratégia climática. Depois, apresenta-se o modelo proposto, descrevem-se as variáveis e os construtos que ele comporta e explica-se como aplicá-lo. Em seguida, são descritos os métodos de coleta e tratamento de dados utilizados na investigação empírica das empresas dos setores nos quais se aplicou o modelo para fins de avaliação de práticas e estratégias climáticas. Na quarta e na quinta partes, os resultados da investigação empírica são apresentados e discutidos. Na última, são feitas considerações finais sobre as lições que a investigação trouxe para as empresas e são fornecidas sugestões para futuras pesquisas na área.

\section{Estratégia climática}

O conceito de estratégia climática é bastante recente e contemporâneo às mudanças climáticas. Neste artigo, adota-se a definição de Hoffman (2006:3):

Estratégia climática é o conjunto de metas e planos de uma corporação visando à redução das emissões de GEE, gerando benefícios associados significativos e/ ou visando responder às alterações produzidas pelas mudanças climáticas nos mercados, nas políticas públicas ou no ambiente físico. 
Entre as ações necessárias à implantação de uma estratégia climática, com vistas à redução das emissões diretas e indiretas de GEE de uma empresa, Hoffman (2006) destaca cinco: eficiência energética; pesquisa e desenvolvimento de tecnologias de baixa intensidade de carbono para processos e produtos; comércio de emissões; redução nas emissões ao longo da cadeia de valor; estratégias de adaptação.

O impacto das mudanças climáticas nas empresas tem sido bastante grande, levando-as a correr riscos de várias naturezas, notadamente, regulamentar, na cadeia de suprimentos, nos produtos e tecnologias associadas, de litígio, de reputação e físicos (Hoffman, 2000, 2006, 2007; Esty e Winston, 2006; Kolk e Pinkse, 2004; Lash e Wellington, 2007).

Segundo Hoffman (2006), quaisquer que sejam as medidas adotadas pelos países para a redução das emissões de GEE, certamente haverá um aumento no preço da energia que afetará diretamente a estrutura de custos de todos os setores da economia. Devido à amplitude dos efeitos das mudanças climáticas no ambiente de negócios atual, as empresas deveriam evoluir de uma preocupação focada no gerenciamento dos custos envolvidos no atendimento às exigências dos órgãos ambientais, para uma postura de reconhecimento da dimensão estratégica da questão climática.

Nossas investigações preliminares apontaram para um consenso, tanto no meio empresarial, como na academia, de que atualmente a grande oportunidade de agregar valor e de criar vantagem competitiva advém das mudanças climáticas. Também observamos um consenso a respeito do fato de que é crucial preparar-se para o advento dessa nova realidade, desenvolvendo estratégias climáticas e adotando práticas críticas para uma implantação bemsucedida, sob pena de ser excluído do mercado definitivamente.

\section{Modelo conceitual proposto}

\section{A representação gráfica}

O Modelo de Estratégias Climáticas (MDEC) é fundamentado em estudos recentes (Hoffman, 2006; Ceres, 2008; CDP, 2006; Pulver, 2007) sobre estratégias climáticas empresariais e em práticas climáticas internacionais benchmarks para a implantação e gestão deste tipo de estratégia, identificadas no âmbito destes estudos. De fato, a maioria dos estudos foi realizada em colaboração com empresas líderes mundiais para compreender a prática do 
gerenciamento climático e buscar soluções para os graves problemas e restrições impostas pelas mudanças climáticas.

Inspirando-se em parte no modelo de Hoffman (2006), o MDEC proposto aqui agrega valor na medida em que incorpora também resultados das pesquisas do Centre for Education and Research in Environmental Strategies (Ceres, 2008) e conceitos de vários outros trabalhos e autores. Inclui conceitos utilizados no Carbon Disclosure Project (CDP, 2006), em suas seis edições, bem como construtos e indicadores de Esty e Winston (2006), de Kolk e Pinkse (2004), de Lash e Wellington (2007) e do próprio Hoffman. Note que alguns dos indicadores apresentados por esses autores são iguais. É o caso dos de Hoffman (2000, 2006) e de Esty e Winston (2006). Por outro lado, Kolk e Pinkse (2004) adotam indicadores utilizados na primeira pesquisa do CDP. No caso de Lash e Wellington (2007), o foco está nas ameaças e oportunidades advindas das mudanças climáticas que impactam tanto a receita quanto os custos das empresas.

O modelo proposto - MDEC - inclui cinco variáveis principais que englobam os principais aspectos de uma estratégia climática (quadro 1). Para facilitar sua operacionalização, essas variáveis foram subdivididas em dimensões, com seus respectivos construtos e indicadores. Lembra-se que um construto é um instrumento que auxilia na mensuração de um conceito ou de uma variável não passível de medição direta (Kerlinger, 1980).

Modelo de Estratégias Climáticas (MDEC)

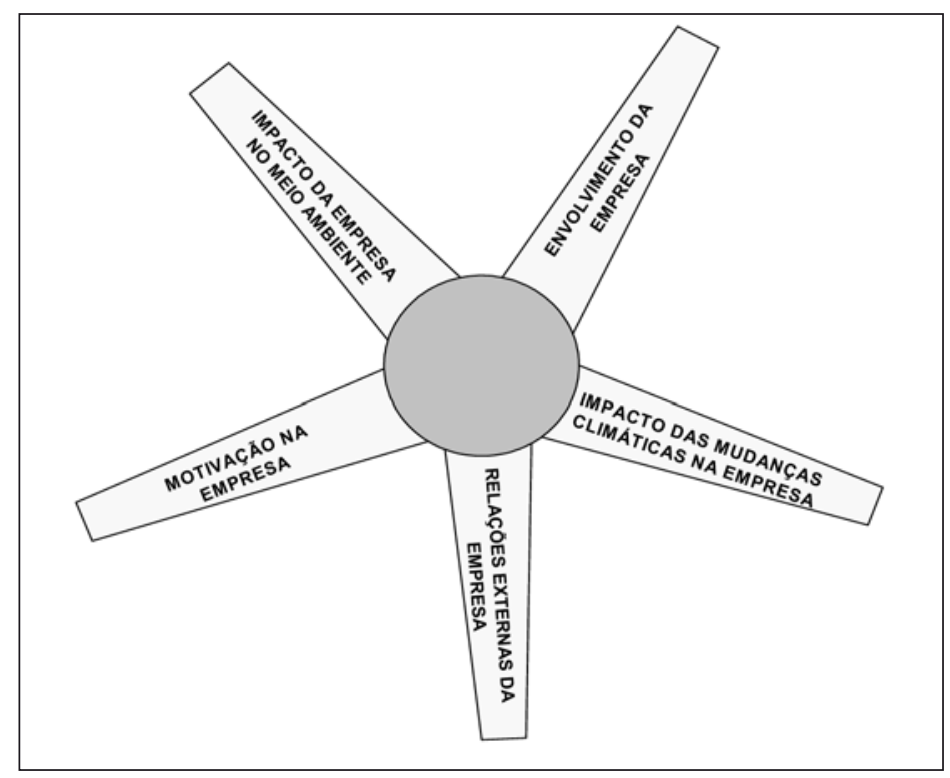


A forma utilizada para representar graficamente o MDEC é a do Sol (figura 1). O símbolo do Sol foi escolhido por sua significância ambiental positiva. Os raios solares representam as cinco variáveis do modelo que convergem para o "objetivo estratégico empresarial", colocado no centro, para enfatizar a importância da conjugação dos principais elementos da estratégia climática e da adequação ou alinhamento deles aos objetivos estratégicos para assegurar sua eficácia, conforme o princípio de strategic fit (Hofer e Schendel, 1978).

\section{As variáveis e suas definições operacionais}

No quadro 1 apresentam-se as variáveis do MDEC acompanhadas de suas respectivas definições operacionais. Conforme Kerlinger (1980), a definição operacional constitui uma ponte entre os conceitos e as observações.

$$
\text { Quadro } 1
$$

\section{As variáveis e suas definições operacionais}

\begin{tabular}{|c|c|}
\hline Variável & Definição operacional \\
\hline $\begin{array}{l}1 \text { Impacto da empresa no } \\
\text { meio ambiente }\end{array}$ & $\begin{array}{l}\text { Grau do impacto da organização no meio ambiente provocado } \\
\text { pelas emissões de GEEs provenientes das operações da empresa, } \\
\text { bem como daquelas decorrentes dos componentes de sua cadeia } \\
\text { de valores e outras emissões associadas }\end{array}$ \\
\hline $\begin{array}{l}2 \text { Impacto das mudanças } \\
\text { climáticas na empresa }\end{array}$ & $\begin{array}{l}\text { Grau do impacto causado na organização pelas oportunidades } \\
\text { e pelas ameaças provenientes das mudanças climáticas, } \\
\text { impulsionando a empresa a desenvolver e implantar uma estratégia } \\
\text { climática }\end{array}$ \\
\hline $\begin{array}{l}3 \text { Envolvimento da } \\
\text { empresa }\end{array}$ & $\begin{array}{l}\text { Grau do envolvimento efetivo da empresa em ações mitigadoras e } \\
\text { eliminatórias de emissões na própria operação e na sua cadeia de } \\
\text { valores }\end{array}$ \\
\hline 4 Motivação na empresa & $\begin{array}{l}\text { Grau de motivação na empresa resultante tanto do lado proativo } \\
\text { da mobilização e divulgação das ações, como da força reativa dos } \\
\text { obstáculos encontrados na implantação de uma estratégia climática }\end{array}$ \\
\hline $\begin{array}{l}5 \text { Relações externas da } \\
\text { empresa }\end{array}$ & $\begin{array}{l}\text { Grau de divulgação e influência da empresa junto ao público, } \\
\text { aos governos e associações empresariais privadas, objetivando o } \\
\text { disclosure das suas ações de redução de emissões, bem como } \\
\text { influência na elaboração de legislação e regulamentos de restrições } \\
\text { ao carbono. Capacidade de aglutinar apoios pertinentes de outras } \\
\text { entidades e do terceiro setor }\end{array}$ \\
\hline
\end{tabular}




\section{Variável 1 - impacto da empresa no meio ambiente}

Lash e Wellington (2007) observam que, ao quantificar suas emissões, a empresa reconhece a importância das mudanças climáticas como fonte de riscos e oportunidades e se capacita para administrar a redução de suas emissões. Enfatizam a necessidade da medição das emissões diretas e indiretas da empresa, além da determinação e do ajuste periódico do nível de referência de emissões para o acompanhamento ao longo do tempo.

No MDEC é adotada a metodologia de classificação de emissões do GHG Protocol Corporate Standard (www.ghgprotocol.org) criada pelo World Resources Institute (WRI) em conjunto com o World Business Council for Sustainable Development (WBCSD), que classifica as emissões em três níveis: escopo 1, escopo 2 e escopo 3.

O quadro 2 apresenta detalhadamente a variável 1 - impacto da empresa no meio ambiente, com suas dimensões, seus construtos, indicadores e valores, bem como os autores e referências utilizadas. As descrições na coluna "indicador" explicam os níveis das emissões (escopos).

Quadro 2

Variável 1: impacto da empresa no meio ambiente

\begin{tabular}{|c|c|c|c|c|}
\hline Dimensão & Construto & Indicador & Prática* & Ref.** \\
\hline Direta & $\begin{array}{l}\text { Emissões } \\
\text { diretas }\end{array}$ & Inventário das emissões diretas (escopo 1) & Sim & $\begin{array}{l}A, B, C, D, \\
E, F\end{array}$ \\
\hline \multirow[t]{6}{*}{ Indireta } & \multirow[t]{6}{*}{$\begin{array}{l}\text { Emissões } \\
\text { indiretas }\end{array}$} & $\begin{array}{l}\text { Inventário das emissões geradas por terceiros } \\
\text { na produção da eletricidade comprada por essa } \\
\text { empresa (escopo 2) }\end{array}$ & $\operatorname{Sim}$ & $\begin{array}{l}A, B, C, D, \\
E, F\end{array}$ \\
\hline & & $\begin{array}{l}\text { Inventário das emissões geradas por terceiros na } \\
\text { produção de insumos e materiais (escopo 3) }\end{array}$ & Sim & $\begin{array}{l}A, B, C, D, \\
E, F\end{array}$ \\
\hline & & $\begin{array}{l}\text { Inventário das emissões decorrentes do uso dos } \\
\text { produtos dessa empresa por terceiros (escopo 3) }\end{array}$ & Sim & $\begin{array}{l}A, B, C, D, \\
E, F\end{array}$ \\
\hline & & $\begin{array}{l}\text { Inventário das emissões decorrentes de viagens } \\
\text { a negócios (escopo 3) }\end{array}$ & Sim & $\begin{array}{l}A, B, C, D, \\
E, F\end{array}$ \\
\hline & & $\begin{array}{l}\text { Inventário das emissões geradas por terceiros nas } \\
\text { atividades terceirizadas por essa empresa (escopo 3) }\end{array}$ & Sim & $\begin{array}{l}A, B, C, D, \\
E, F\end{array}$ \\
\hline & & $\begin{array}{l}\text { Inventário das emissões decorrentes do descarte } \\
\text { dos produtos dessa empresa (escopo 3) }\end{array}$ & Sim & $\begin{array}{l}A, B, C, D, \\
E, F\end{array}$ \\
\hline
\end{tabular}

* Depende do tipo de setor.

** A - Hoffman (2000, 2006); B - Esty e Winston (2006); C - Kolk e Pinkse (2004); D - Lash e Wellington (2007); E - CDP; F - Ceres. 


\section{Variável 2 - impacto das mudanças climáticas na empresa}

O potencial de indução das mudanças climáticas para a implantação de estratégias climáticas nas empresas varia segundo os setores em que se inserem, tendo em vista que as mudanças climáticas impõem ameaças e criam oportunidades diferentes para as organizações, segundo o setor (Hoffman, 2006; Kolk e Pinkse, 2004).

No MDEC proposto os fatores que impulsionam as empresas a estabelecerem uma estratégia climática são denominados indutores. Segundo Hoffman (2006) e Esty e Winston (2006), as emissões isoladamente não revelam o grau de exposição da empresa às restrições ao carbono. Cabe considerar também os impactos potenciais sobre a linha de produtos e serviços, bem como as pressões crescentes de cunho ambiental cada vez maiores, exercidas pelos stakeholders, que afetam a competitividade da empresa.

Entre os principais itens que devem ser levados em conta para a avaliação da exposição de uma empresa em uma economia com restrições ao carbono, além do inventário de emissões diretas e indiretas ao longo de sua cadeia de valor, destacam-se os seguintes: o perfil de emissões da empresa em relação aos concorrentes, a exposição quanto aos impactos climáticos do setor na qual a empresa está inserida em relação a outros setores, o ambiente regulatório atual e futuro de restrição ao carbono, as tendências dos custos e as mudanças nas preferências dos consumidores. Além disso, a identificação dos riscos e das oportunidades impostas pelas mudanças climáticas às empresas deve levar em conta as condições atuais e futuras, tanto do perfil de emissões da empresa quanto do macroambiente em uma economia com restrições ao carbono.

O quadro 3 apresenta a variável 2 com as suas dimensões, construtos, indicadores e valores, bem como os autores e referências utilizadas.

Quadro 3

Variável 2: impacto das mudanças climáticas na empresa Dimensão: indutora

\begin{tabular}{|l|l|l|l|}
\hline Construto & \multicolumn{1}{|c|}{ Indicador } & \multicolumn{1}{|c|}{ Prática* } & \multicolumn{1}{|c|}{ Ref. ** } \\
\hline Novos mercados & Demanda de produtos com baixa & Grau de importância & A, B, C, \\
& emissão de GEEs & Likert $\geq 4$ & E, F \\
& Demanda de serviços com baixo grau de & Grau de importância & A, B, C, \\
& emissão de GEEs & Likert $\geq 4$ & E, F \\
& Salto no padrão tecnológico do setor & Grau de importância & A, B, D, E \\
& Likert $\geq 4$ & \\
\hline
\end{tabular}

Continua 


\begin{tabular}{|c|c|c|c|}
\hline Construto & Indicador & Prática* & Ref. ** \\
\hline Competitividade & $\begin{array}{l}\text { Aumento da eficiência operacional da } \\
\text { empresa } \\
\text { Aumento da competitividade junto à } \\
\text { concorrência } \\
\text { Redução de custos }\end{array}$ & $\begin{array}{l}\text { Grau de importância } \\
\text { Likert } \geq 4 \\
\text { Grau de importância } \\
\text { Likert } \geq 4 \\
\text { Grau de importância } \\
\text { Likert } \geq 4\end{array}$ & $\begin{array}{l}\text { A, B } \\
\text { A, B, C, D, } \\
\text { E, F } \\
\text { A, B, C, } \\
D, E\end{array}$ \\
\hline \begin{tabular}{|l|} 
Fatores \\
intangíveis
\end{tabular} & $\begin{array}{l}\text { Reputação positiva da empresa e de sua } \\
\text { marca } \\
\text { Prática da responsabilidade social } \\
\text { Consistência com a cultura e histórico da } \\
\text { empresa } \\
\text { Aperfeiçoamento da gestão de riscos }\end{array}$ & $\begin{array}{l}\text { Grau de importância } \\
\text { Likert } \geq 4 \\
\text { Grau de importância } \\
\text { Likert } \geq 4 \\
\text { Grau de importância } \\
\text { Likert } \geq 4 \\
\text { Grau de importância } \\
\text { Likert } \geq 4 \\
\end{array}$ & $\begin{array}{l}\text { A, B, C } \\
\text { E, F } \\
A, B, C \\
A, B, C \\
A, B, D\end{array}$ \\
\hline $\begin{array}{l}\text { Fatores } \\
\text { financeiros }\end{array}$ & $\begin{array}{l}\text { Possibilidade de geração de créditos de } \\
\text { carbono } \\
\text { Novas fontes de financiamento (fundos } \\
\text { de investimento) } \\
\text { Incentivos fiscais }\end{array}$ & $\begin{array}{l}\text { Grau de importância } \\
\text { Likert } \geq 4 \\
\text { Grau de importância } \\
\text { Likert } \geq 4 \\
\text { Grau de importância } \\
\text { Likert } \geq 4\end{array}$ & $\begin{array}{l}\text { A, B, C, D, } \\
\text { E, F } \\
\text { A, B, C } \\
D, E \\
\text { A }\end{array}$ \\
\hline $\begin{array}{l}\text { Exposição a } \\
\text { riscos }\end{array}$ & $\begin{array}{l}\text { Legislação restritiva quanto a emissões } \\
\text { de GEEs } \\
\text { Padrões restritivos de emissões de GEEs } \\
\text { de produtos } \\
\text { Padrões restritivos de emissões de GEEs } \\
\text { de processos } \\
\text { Vulnerabilidade física de ativos } \\
\text { Aumento dos custos referentes a insumos } \\
\text { da empresa } \\
\text { Aumento dos custos referentes à energia } \\
\text { consumida } \\
\text { Aumento expressivo no custo de apólices } \\
\text { de seguro } \\
\text { Mudança na atitude dos consumidores } \\
\text { ou clientes } \\
\text { Pressão de ONGs } \\
\text { Ocorrência de litígio }\end{array}$ & $\begin{array}{l}\text { Grau de importância } \\
\text { Likert } \geq 4 \\
\text { Grau de importância } \\
\text { Likert } \geq 4 \\
\text { Grau de importância } \\
\text { Likert } \geq 4 \\
\text { Grau de importância } \\
\text { Likert } \geq 4 \\
\text { Grau de importância } \\
\text { Likert } \geq 4 \\
\text { Grau de importância } \\
\text { Likert } \geq 4 \\
\text { Grau de importância } \\
\text { Likert } \geq 4 \\
\text { Grau de importância } \\
\text { Likert } \geq 4 \\
\text { Grau de importância } \\
\text { Likert } \geq 4 \\
\text { Grau de importância } \\
\text { Likert } \geq 4\end{array}$ & $\begin{array}{l}\text { A, B, C, D, } \\
\text { E, F } \\
\text { A, B, E } \\
\text { A, B, E } \\
\text { A, B, C, D, } \\
\text { E, F } \\
\text { A, B, C, } \\
\text { D, E } \\
\text { A, B, C, D } \\
\text { A, B, D } \\
\text { A, B, D, E } \\
\text { A, B } \\
\text { A, B, D, E }\end{array}$ \\
\hline
\end{tabular}

* Depende do tipo de setor.

** A - Hoffman (2000, 2006); B - Esty e Winston (2006); C - Kolk e Pinkse (2004); D - Lash e Wellington (2007); E - CDP; F - Ceres. 


\section{Variável 3 - envolvimento da empresa}

A definição de metas de redução de GEEs e o acompanhamento periódico do nível das emissões da empresa são essenciais para uma estratégia climática. A redução de emissões pode ser realizada no âmbito da empresa e em sua cadeia de valores. Diversas empresas vão mais longe e avaliam as possibilidades de redução de GEEs em todas as fases do ciclo de vida de seus produtos, desde a fabricação de seus componentes por terceiros até o momento em que o produto é descartado no final de sua vida útil. Esse levantamento dos impactos ao longo do ciclo de vida do produto é denominado life cicle assessment — LCA (Esty e Winston, 2006).

Argumenta-se que o planejamento das ações para a implantação de uma estratégia climática visando à redução das emissões da empresa, à mitigação dos riscos e ao aproveitamento das oportunidades presentes em um ambiente com restrições ao carbono, se bem desenvolvido e implantado, possibilitará o posicionamento da empresa de forma positiva junto ao governo, às ONGs e ao público em geral.

Segundo Hoffman (2006), em muitos casos identifica-se facilmente as ações de baixo custo e risco para a redução de emissões de GEEs. Normalmente essas ações se referem à eficiência energética, a mudanças de comportamento e a melhorias em processos. No longo prazo, as empresas podem desenvolver projetos de redução de emissões mais elaborados, envolvendo inovações tecnológicas para uma redução acentuada das emissões de GEEs. Também existem oportunidades de compensação de emissões e de redução de emissões além do contexto de operações da empresa, como por exemplo: projetos florestais de sequestro de carbono, aquisição de ativos de baixa emissão e comércio de créditos de carbono.

Muitas empresas estabelecem metas tanto para a eficiência energética quanto para a redução de emissões de GEEs. As metas de eficiência energética resultam rapidamente em benefícios financeiros para a empresa no curto prazo e, portanto, são geralmente identificadas como estratégicas. O benefício financeiro proveniente das metas de redução de GEEs é de quantificação mais difícil e está mais voltado para o longo prazo (Hoffman, 2006).

Para aumentar a motivação e incentivar a criatividade na empresa, recomenda-se adotar metas de redução de GEEs ambiciosas. Muitas empresas ultrapassam as metas, antes dos prazos estabelecidos, principalmente quando nunca implantaram medidas de eficiência energética. Além disso, as estratégias referentes à eficiência energética normalmente estão relacionadas a processos discretos e intensivos em energia e as responsabilidades por suas implantações são das unidades operacionais que têm ingerência direta sobre o processo, o que facilita a implantação. No caso das metas de redução de 
emissões de GEEs, deve-se considerar a empresa como um todo e os prazos envolvidos bem maiores. Ao mesmo tempo, cabe estabelecer metas específicas para cada fábrica, ou unidade de negócio da empresa, de modo a levar em conta suas particularidades e permitir um tratamento prioritário das áreas mais problemáticas (Esty e Winston, 2006).

Outros dois fatores de grande importância são a existência de um comitê executivo de alto nível para o acompanhamento dos resultados das medidas implantadas para a redução de GEEs e a contratação de auditoria independente. O quadro 4 apresenta a variável 3 - envolvimento da empresa - com as suas dimensões, seus construtos, indicadores e valores, bem como os autores e as referências utilizadas.

\section{Quadro 4}

\section{Variável 3: envolvimento da empresa Dimensão: escopo de ação}

\begin{tabular}{|c|c|c|c|}
\hline Construto & Indicador & Prática* & Ref.** \\
\hline \multirow{14}{*}{$\begin{array}{l}\text { Redução de } \\
\text { emissões na } \\
\text { empresa }\end{array}$} & Metas de redução de emissões próprias de GEEs & Sim & $\begin{array}{l}\text { A, B, C, } \\
D, E, F\end{array}$ \\
\hline & $\begin{array}{l}\text { Desenvolvimento de produtos com baixa ou nenhuma } \\
\text { emissão de GEEs }\end{array}$ & Sim & $\begin{array}{l}\text { A, B, C, } \\
D, E, F\end{array}$ \\
\hline & Aperfeiçoamento de produto(s) visando reduzir GEEs & Sim & $\begin{array}{l}\text { A, B, C, } \\
D, E, F\end{array}$ \\
\hline & Programa de eficiência energética & Sim & $\begin{array}{l}\text { A, B, C, } \\
D, E, F\end{array}$ \\
\hline & $\begin{array}{l}\text { Transformação de resíduos do processo produtivo em } \\
\text { coprodutos }\end{array}$ & Sim & $A, B$ \\
\hline & Redesenho do processo produtivo visando reduzir GEEs & Sim & $A, B, C, F$ \\
\hline & $\begin{array}{l}\text { Utilização de processo produtivo de baixa emissão de } \\
\text { GEEs }\end{array}$ & Sim & $\begin{array}{l}\text { A, B, C, } \\
D, E, F\end{array}$ \\
\hline & $\begin{array}{l}\text { Substituição de equipamentos do processo produtivo } \\
\text { visando reduzir emissões de GEEs }\end{array}$ & $\operatorname{sim}$ & $A, B$ \\
\hline & $\begin{array}{l}\text { Retroffiting de equipamentos do processo produtivo } \\
\text { visando reduzir emissões de GEEs }\end{array}$ & Sim & $A, B$ \\
\hline & $\begin{array}{l}\text { Reaproveitamento de efluentes e gases no próprio } \\
\text { processo produtivo visando reduzir emissões de GEEs }\end{array}$ & $\operatorname{sim}$ & $\begin{array}{l}A, B, C \\
E, F\end{array}$ \\
\hline & Utilização de material reciclado como insumo para a produção & $\operatorname{sim}$ & $A, B, F$ \\
\hline & Utilização de energia renovável & $\operatorname{sim}$ & $\begin{array}{l}\text { A, B, C, } \\
E, F\end{array}$ \\
\hline & Cogeração de energia & $\operatorname{sim}$ & $A, B$ \\
\hline & Programa de substituição de combustíveis fósseis & $\operatorname{sim}$ & $\begin{array}{l}\text { A, B, C, } \\
E, F\end{array}$ \\
\hline
\end{tabular}




\begin{tabular}{|c|c|c|c|}
\hline \multirow[t]{9}{*}{ Construto } & Indicador & Prática* & Ref.** \\
\hline & Venda de participação acionária em ativos com alto GEE & $\operatorname{Sim}$ & $A, B$ \\
\hline & $\begin{array}{l}\text { Aquisição de participação acionária em ativos com baixo } \\
\text { GEE }\end{array}$ & Sim & $A, B$ \\
\hline & Incentivo ao trabalho remoto (telecommuting) & Sim & $A, B$ \\
\hline & Incentivo à substituição de viagens por teleconferências & Sim & $A, B$ \\
\hline & Sistema de gerenciamento ambiental (ISO 14000 ou outro) & Sim & $A, B$ \\
\hline & Sequestro geológico de $\mathrm{CO}_{2}$ (subsolo) & Sim & $A, B, F$ \\
\hline & Sequestro terrestre de $\mathrm{CO}_{2}$ (plantio de árvores) & Sim & $A, B, F$ \\
\hline & Instalações prediais ecológicas (leed buildings) & Sim & $A, B$ \\
\hline \multirow{4}{*}{$\begin{array}{l}\text { Redução de } \\
\text { emissões na } \\
\text { cadeia de valores } \\
\text { expandida }\end{array}$} & Metas de redução de emissões de GEEs na cadeia de valor & Sim & $A, B, C, E$ \\
\hline & $\begin{array}{l}\text { Análise do ciclo de vida do produto - LCA (life cicle } \\
\text { assessment) }\end{array}$ & Sim & $\begin{array}{l}\text { A, B, C, } \\
E, F\end{array}$ \\
\hline & Auditoria de emissões na cadeia de suprimentos & Sim & $A, B, C$ \\
\hline & $\begin{array}{l}\text { Redução de emissões na logística e distribuição dos } \\
\text { produtos }\end{array}$ & $\operatorname{sim}$ & $\begin{array}{l}\text { A, B, C, } \\
D, E\end{array}$ \\
\hline \multirow[t]{3}{*}{$\begin{array}{l}\text { Compensação de } \\
\text { emissões }\end{array}$} & Compra/venda de créditos de carbono & Sim & $\begin{array}{l}\text { A, B, C } \\
D, E, F\end{array}$ \\
\hline & $\begin{array}{l}\text { Ações voluntárias visando à compensação de emissões } \\
\text { próprias }\end{array}$ & Sim & $A, B, C$ \\
\hline & $\begin{array}{l}\text { Parcerias com empresas, ONGs ou governo em projetos } \\
\text { de redução de emissões de GEEs }\end{array}$ & Sim & $A, B, C, F$ \\
\hline \multirow[t]{5}{*}{$\begin{array}{l}\text { Acompanhamento } \\
\text { de emissões }\end{array}$} & $\begin{array}{l}\text { Referencial de quantidade de emissões e ano para } \\
\text { acompanhamento das reduções de emissões de GEEs }\end{array}$ & Sim & $\begin{array}{l}A, B, C \\
E, F\end{array}$ \\
\hline & $\begin{array}{l}\text { Comitê executivo ou similar responsável por questões } \\
\text { referentes às mudanças climáticas }\end{array}$ & Sim & $A, B, E, F$ \\
\hline & $\begin{array}{l}\text { Acompanhamento e aferição das emissões por terceira } \\
\text { parte }\end{array}$ & Sim & $\begin{array}{l}A, B, C \\
E, F\end{array}$ \\
\hline & $\begin{array}{l}\text { Equipamentos para monitoramento de emissões } \\
\text { próprias de GEE }\end{array}$ & Sim & $A, B, C, F$ \\
\hline & Benchmark para a redução de emissões de GEEs & Sim & $A, B$ \\
\hline
\end{tabular}

* Depende do tipo de setor.

** A - Hoffman (2000, 2006); B - Esty e Winston (2006); C - Kolk e Pinkse (2004); D - Lash e Wellington (2007); E - CDP; F - Ceres.

\section{Variável 4 - motivação da empresa}

Devido à natureza complexa e de longo prazo das questões referentes às mudanças climáticas, o apoio do corpo funcional da empresa é fundamental. Os 
empregados desenvolvem formas criativas para alcançar suas metas quando essas são claramente definidas e eles percebem as relações entre a visão e os valores da empresa (Hoffman, 2006).

Enquanto o engajamento da liderança é imprescindível para posicionar as questões climáticas como prioritárias, o comprometimento da gerência intermediária é fundamental para a implantação efetiva dos programas e das ações para a redução e eliminação de emissões de GEEs. Esse comprometimento pode ser incentivado com a criação de comitês com autoridade para administrar as metas pertinentes a estratégias climáticas e criar incentivos financeiros vinculados ao alcance dessas metas e com o revezamento de funções entre os executivos das áreas operacionais e do meio ambiente (Esty e Winston, 2006).

Além disso, é importante identificar os departamentos que iniciarão o processo de mudança para a implantação da estratégia e/ou práticas climáticas, os que implantarão os programas e os que adotarão uma postura de resistência às mudanças. $\mathrm{O}$ apoio dos profissionais mais experientes também é valioso. A meta principal nesse processo é transferir as questões relativas às mudanças climáticas da periferia para o centro da organização (Hoffman, 2006).

Algumas empresas promovem e incentivam ações relevantes para suas estratégias climáticas, tais como: o plantio de árvores, a compra e utilização de veículos com baixo nível de emissões, a aquisição de bicicletas pelos empregados, a premiação e o reconhecimento público das iniciativas individuais ambientais e a realização de programas de treinamento em melhores práticas climáticas.

A publicação periódica em relatórios internos das realizações e das metas climáticas da empresa é fundamental para incentivar os empregados, pois promovem a divulgação das ações e o comprometimento da empresa com as questões climáticas. Além disso, os relatórios internos ajudam a difundir junto ao corpo funcional as prioridades da empresa quanto às mudanças climáticas e o quanto essas prioridades colaboram para o alcance dos objetivos da empresa.

Para refletir essas condições, foi concebida a variável 4 - motivação na empresa (quadro 5), associada diretamente ao grau de motivação no ambiente empresarial para a implantação de uma estratégia climática. 
Quadro 5

\section{Variável 4: motivação na empresa}

\begin{tabular}{|c|c|c|c|c|}
\hline Dimensão & Construto & Indicador & Prática* & Ref** \\
\hline Proativa & Mobilização & $\begin{array}{l}\text { Participação direta da alta } \\
\text { administração } \\
\text { Participação direta dos } \\
\text { empregados } \\
\text { Grau de autonomia dos } \\
\text { empregados } \\
\text { Bônus financeiro vinculado a } \\
\text { metas climáticas } \\
\text { Programa de conscientização } \\
\text { dos empregados } \\
\text { Programa de treinamento dos } \\
\text { empregados } \\
\text { Áreas envolvidas } \\
\text { Áreas líderes no início da } \\
\text { implantação da estratégia }\end{array}$ & $\begin{array}{l}\text { Grau de importância } \\
\text { Likert } \geq 4 \\
\text { Grau de importância } \\
\text { Likert } \geq 4 \\
\text { Grau de importância } \\
\text { Likert } \geq 4 \\
\text { Grau de importância } \\
\text { Likert } \geq 4 \\
\text { Grau de importância } \\
\text { Likert } \geq 4 \\
\text { Grau de importância } \\
\text { Likert } \geq 4 \\
\text { Grau de importância } \\
\text { Likert } \geq 4 \\
\text { Grau de importância } \\
\text { Likert } \geq 4\end{array}$ & $\begin{array}{l}\text { A, B, C, D, } \\
E, F \\
A, B \\
A, B \\
A, B, C, D, \\
E, F \\
A, B \\
A, B \\
A, B \\
\text { A }\end{array}$ \\
\hline & Divulgação & $\begin{array}{l}\text { Comunicado CEO } \\
\text { Relatórios internos } \\
\text { Intranet }\end{array}$ & $\begin{array}{l}\text { Grau de importância } \\
\text { Likert } \geq 4 \\
\text { Grau de importância } \\
\text { Likert } \geq 4 \\
\text { Grau de importância } \\
\text { Likert } \geq 4\end{array}$ & $\begin{array}{l}\text { A, B, C, D, } \\
\text { E, F } \\
\text { A, B, C, D, } \\
\text { E, F } \\
\text { A, B }\end{array}$ \\
\hline Reativa & Obstáculos & $\begin{array}{l}\text { Fontes de resistências } \\
\text { Carência de habilidades } \\
\text { Financeiros } \\
\text { Gerência intermediária }\end{array}$ & $\begin{array}{l}\text { Grau de resistência } \\
\text { Likert } \geq 2 \\
\text { Grau de resistência } \\
\text { Likert } \geq 2 \\
\text { Grau de resistência } \\
\text { Likert } \geq 2 \\
\text { Grau de resistência } \\
\text { Likert } \geq 2\end{array}$ & $\begin{array}{l}A, B \\
A, B \\
A, B \\
A, B\end{array}$ \\
\hline
\end{tabular}

* Depende do tipo de setor.

** A - Hoffman (2000, 2006); B - Esty e Winston (2006); C - Kolk e Pinkse (2004); D - Lash e Wellington (2007); E-CDP; F-Ceres. 


\section{Variável 5 - relações externas da empresa}

Segundo Esty e Winston (2006), a comunicação da empresa com o público externo é fundamental para a boa governança climática, a promoção da transparência, a divulgação das ações e a manutenção de um diálogo construtivo com os diversos stakeholders. A divulgação das ações em prol do meio ambiente, bem como das ações referentes às reduções de emissões de GEE ajudam a construir uma opinião pública favorável sobre a organização. A divulgação de informações referentes aos atributos ambientais (verdes) de produtos e serviços também contribui para posicionar a empresa de forma positiva junto ao mercado, desde que os dados sejam verdadeiros. Para o sucesso dessa comunicação externa é muito importante identificar os diversos públicos-alvo, tais como: ONGs, governo, comunidade e investidores.

As parcerias externas também são indispensáveis ao sucesso das práticas e estratégias climáticas das empresas. A melhor maneira de conhecer a sua imagem junto ao público externo é por meio da realização de parcerias com outras organizações (Esty e Winston, 2006). Assim, as ONGs podem ajudar muito as empresas a conhecer a percepção que o público tem de suas marcas. Como observado por Hoffman (2006), as alianças com ONGs podem proporcionar credibilidade para ambas as partes.

O bom relacionamento com o governo também é essencial, sobretudo para proporcionar credibilidade e condições de influenciar na elaboração das medidas, normas e regulamentos restritivos ao carbono que, sem dúvida, afetarão a empresa e seu ambiente competitivo.

A comunidade de investidores também é outro stakeholder importante, uma vez que de forma crescente os riscos e a conduta ambiental das empresas influenciam na tomada de decisão sobre os investimentos.

A variável 5 - relações externas (quadro 6) está associada diretamente à forma de atuação da empresa no ambiente externo no que se refere à divulgação de suas metas e à formação de parcerias visando à redução ou à eliminação de emissões de GEEs. É composta pela dimensão denominada escopo e abrange os construtos "parcerias" e "divulgação". 
Quadro 6

Variável 5: relações externas da empresa

Dimensão: escopo

\begin{tabular}{|c|c|c|c|}
\hline Construto & Indicador & Prática* & Ref.** \\
\hline \multirow{5}{*}{ Parcerias } & Parcerias com outras empresas & Grau de importância Likert $\geq 4$ & $A, B, C, F$ \\
\hline & Parcerias com ONGs & Grau de importância Likert $\geq 4$ & $A, B, C, F$ \\
\hline & Parcerias com governos & Grau de importância Likert $\geq 4$ & $A, B, C, F$ \\
\hline & Parcerias com associações de classe & Grau de importância Likert $\geq 4$ & $A, B, C, F$ \\
\hline & Parcerias com investidores & Grau de importância Likert $\geq 4$ & $A, B, C, F$ \\
\hline \multirow{4}{*}{ Divulgação } & $\begin{array}{l}\text { Publicação de relatórios referentes a } \\
\text { questões climáticas }\end{array}$ & Grau de importância Likert $\geq 4$ & $\begin{array}{l}\mathrm{A}, \mathrm{B}, \mathrm{C}, \\
\mathrm{E}, \mathrm{F}\end{array}$ \\
\hline & $\begin{array}{l}\text { Participação no Carbon Disclosure } \\
\text { Project - CDP }\end{array}$ & Grau de importância Likert $\geq 4$ & $C, E, F$ \\
\hline & Comunicado CEO & Grau de importância Likert $\geq 4$ & $A, B, C, F$ \\
\hline & Uso da mídia & Grau de importância Likert $\geq 4$ & $A, B, C, F$ \\
\hline
\end{tabular}

* Depende do tipo de setor.

** A - Hoffman (2000, 2006); B - Esty e Winston (2006); C - Kolk e Pinkse (2004); D - Lash e Wellington (2007); E - CDP; F - Ceres.

\section{Metodologia para aplicação do MDEC}

Na pesquisa os seguintes passos foram recomendados para utilizar o modelo proposto como instrumento de avaliação das práticas e estratégias climáticas empresariais:

- selecionar para as variáveis 1, 2 e 3, entre as práticas benchmark internacionais apresentadas no MDEC, as mais apropriadas para o setor e a empresa sob análise. No caso das variáveis 4 e 5 todas as práticas internacionais apresentadas no MDEC devem ser utilizadas para quaisquer setores/empresas;

v coletar, por meio de questionário estruturado, os dados referentes aos indicadores de cada construto do MDEC e verificar para cada indicador selecionado se os valores estão compatíveis com as práticas internacionais;

v propor alterações na estratégia empresarial e/ou nas práticas adotadas para sua implantação, a fim de alcançar as práticas internacionais, no caso de haver incongruências entre os valores dos indicadores coletados na empresa e os referentes às práticas internacionais. 


\section{Métodos de pesquisa}

Antes de apresentar os resultados da aplicação do MDEC nos setores mencionados, seguindo os passos descritos acima, fornecem-se detalhes a respeito da coleta e tratamento dos dados, bem como sobre o universo investigado e tamanho da amostra. Também são elencadas as hipóteses que foram testadas no âmbito da investigação.

\section{Universo, amostra e sujeitos}

Escolheu-se como universo para aplicação do modelo proposto para ferramenta de avaliação de práticas e estratégias climáticas, dois grupos de empresas, cada um de um setor diferente. O primeiro grupo foi composto por $42 \mathrm{em}$ presas fabricantes de papel e celulose membros da Associação Brasileira de Celulose e Papel (Bracelpa) que representam, aproximadamente, 99\% da produção de celulose e $80 \%$ da produção de papel no Brasil. O segundo grupo foi composto por 24 empresas associadas à Associação Nacional dos Fabricantes de Veículos Automotores (Anfavea), que constituem a totalidade de empresas de autoveículos (automóveis, comerciais leves, caminhões, ônibus) e máquinas agrícolas automotrizes (tratores de rodas e de esteiras, colheitadeiras e retroescavadeiras) com instalações industriais no Brasil.

Os setores de papel e celulose e automotivo foram escolhidos devido à relevância na economia nacional, exposição às mudanças climáticas e o importante papel como responsáveis pelos impactos climáticos. De fato, a cadeia produtiva do setor de papel e celulose é fortemente dependente de recursos naturais e os bens produzidos pelo setor automotivo podem contribuir significativamente para a redução das emissões de GEEs ao longo de seus ciclos de vida.

O tamanho da amostra de cada setor foi calculado a partir da fórmula de Rea e Parker (2000), apropriada para pequenas populações. Para um intervalo de confiança de $95 \%$, ou seja, um grau de significância de 5\%, a amostra foi de 27 empresas de papel e celulose e de 19 empresas do setor automotivo, com uma margem de erro de $12 \%$ e $10 \%$, respectivamente. Os sujeitos escolhidos para participar da pesquisa foram os executivos seniores dessas empresas.

\section{Coleta e tratamento de dados}

Para a coleta de dados junto às empresas da amostra foi realizado um levantamento de percepções, do tipo survey, com auxílio de um questionário 
predominantemente estruturado, construído com base nos construtos e indicadores do MDEC.

O questionário incluiu questões fechadas ponderadas em uma escala Likert de cinco alternativas, questões de escolha múltipla com alternativas variadas e também questões dicotômicas, do tipo sim/não. Adicionalmente, foram introduzidas algumas questões abertas.

Antes da aplicação da pesquisa à amostra, o questionário foi submetido a um pré-teste com especialistas em temas ambientais e em créditos de carbono para verificar sua clareza e sua capacidade de captação dos dados e das informações necessárias para responder às questões.

Em seguida, as empresas da amostra foram convidadas por meio da Bracelpa e da Anfavea a participar do survey. Para garantir seu envolvimento, primeiro, todos os executivos seniores dessas empresas foram contatados por telefone.

A aplicação do questionário foi realizada via internet, o que permitiu o imediato armazenamento das informações em um banco de dados eletrônico, facilitando sua consolidação e eliminando o risco de erros de digitação.

Após uma pré-análise das respostas para verificar a consistência das mesmas com as perguntas do questionário referentes às variáveis do MDEC, os dados foram agrupados de acordo com os construtos e indicadores. Em seguida, esses dados foram tabulados e submetidos a um tratamento estatístico descritivo (distribuição gráfica de frequências, médias e desvio padrão). Foram realizados testes estatísticos do tipo t-student para comparar as práticas das empresas pesquisadas com as de benchmarks internacionais, bem como testes do tipo não paramétrico Kruskal-Wallis (Anderson, Sweeney e Williams, 2005; McClave, Benson e Sincich, 2001) para verificar possíveis diferenças entre as médias dos dois setores escolhidos para o estudo. O uso do teste não paramétrico Kruskal-Wallis foi adotado por ser mais robusto ante a não normalidade das distribuições das variáveis representadas pelos indicadores dos construtos. Os cálculos estatísticos foram realizados com o software SPSS versão 13.0 e o pacote estatístico da Microsoft Excel.

No caso das variáveis 1 e 3, os dados coletados foram submetidos apenas a um tratamento descritivo, uma vez que não foi atribuída escala de valor (tipo Likert) às práticas internacionais.

Quanto aos dados pertinentes às variáveis 2, 4 e 5, cinco hipóteses foram testadas estatisticamente, tanto para a comparação com as práticas internacionais (teste-t) quanto para a comparação entre os setores (teste Kruskal-Wallis). 


\section{Hipóteses}

A seguir apresentam-se as hipóteses e as respectivas variáveis do MDEC às quais correspondem.

\section{1a hipótese (variável 2)}

Os indutores das estratégias climáticas das empresas brasileiras dos setores de papel e celulose e automotivo: 1(a) - têm poder de indução semelhante para os dois setores; 1(b) - têm, individualmente, poder de indução inferior às práticas internacionais no setor de papel e celulose; 1(c) — têm, individualmente, poder de indução inferior às práticas internacionais no setor automotivo.

\section{$2^{\mathrm{a}}$ hipótese (variável 4)}

O grau de utilização dos mecanismos favoráveis à criação de um clima de motivação positiva importante para o sucesso da estratégia climática nas empresas brasileiras dos setores de papel e celulose e automotivo: 2(a) - é semelhante para os dois setores; 2(b) - é inferior às práticas internacionais para o setor de papel e celulose; $2(\mathrm{c})$ — é inferior às práticas internacionais para o setor automotivo.

\section{3a hipótese (variável 4)}

O peso dos fatores que prejudicam a criação do clima de motivação positiva favorável ao sucesso das estratégias climáticas nas empresas brasileiras dos setores de papel e celulose e automotivo: 3(a) — é semelhante para os dois setores; 3(b) - é superior às práticas internacionais para o setor de papel e celulose; 3(c) — é superior às práticas internacionais para o setor automotivo.

\section{4ª hipótese (variável 5)}

O grau de utilização dos mecanismos favoráveis ao incremento do relacionamento externo importante para o sucesso da estratégia climática nas empresas brasileiras dos setores de papel e celulose e automotivo: 4(a) - é semelhante para os 
dois setores; 4(b) - é inferior às práticas internacionais para o setor de papel e celulose; 4(c) - é inferior às práticas internacionais para o setor automotivo.

\section{5aㅗ hipótese (variável 5)}

O grau de utilização dos mecanismos favoráveis ao incremento da divulgação externa importante para o sucesso da estratégia climática nas empresas brasileiras dos setores de papel e celulose e automotivo: 5(a) — é semelhante para os dois setores; 5 (b) - é inferior às práticas internacionais para o setor de papel e celulose; 5(c) - é inferior às práticas internacionais para o setor automotivo.

\section{Resultados}

Um dos resultados mais relevantes da aplicação do ferramental nos setores investigados foi de descobrir que aproximadamente $1 / 3$ das empresas nesses setores não realiza medição das emissões de GEEs (variável 1). De fato, conforme pode ser observado na tabela 1, 37\% e 30\% das empresas do setor automotivo e de papel e celulose, respectivamente, não realizam qualquer tipo de medição. Quanto aos gases objeto de medição dentro da classificação do GHG protocol, $47 \%$ e $67 \%$ das empresas do setor automotivo e de papel e celulose, respectivamente, medem as emissões diretas de escopo 1. É importante registrar que no setor automotivo, quanto às emissões indiretas de escopo 3, somente uma empresa (5\%) da amostra mede as emissões geradas por terceiros na produção dos insumos e materiais utilizados e as decorrentes da utilização dos veículos por terceiros durante suas vidas úteis. No caso do setor de papel e celulose, $37 \%$ da amostra medem as emissões geradas por terceiros na produção dos insumos e materiais utilizados e somente $11 \%$ medem as emissões decorrentes da utilização dos produtos por terceiros durante suas vidas úteis.

Tabela 1

Classificação das emissões de GEEs - GHG protocol

\begin{tabular}{|clcc|}
\hline Classificação das emissões & $\begin{array}{c}\text { Automotivo } \\
(\%)\end{array}$ & $\begin{array}{c}\text { Papel e celulose } \\
(\%)\end{array}$ \\
\hline 1 Não realiza medição de emissões de GEEs & 37 & 30 \\
2 Emissões diretas (escopo 1) & 47 & 67 \\
3 Emissões indiretas geradas por terceiros (escopo 2) & 11 & 30 \\
\hline
\end{tabular}

Continua 


\begin{tabular}{|clc|}
\hline Classificação das emissões & $\begin{array}{c}\text { Automotivo } \\
(\%)\end{array}$ & $\begin{array}{c}\text { Papel e celulose } \\
(\%)\end{array}$ \\
\hline $4 \quad \begin{array}{l}\text { Emissões indiretas geradas por terceiros na produção } \\
\text { (escopo 3) }\end{array}$ & 5 & 37 \\
$5 \quad$ Emissões indiretas geradas pela utilização dos produtos & 5 & 11 \\
$\quad$ (escopo 3) & 5 & 7 \\
6 Emissões indiretas geradas por viagens (escopo 3) & 0 & 15 \\
7 Emissões indiretas geradas por terceiros nas atividades & & 11 \\
$\quad$ (escopo 3) & 0 & 0 \\
8 Emissões indiretas geradas por descarte (escopo 3) & 5 & \\
9 Outros & & \\
\hline
\end{tabular}

Quanto aos indicadores de medida de GEEs, as emissões totais em toneladas de $\mathrm{CO}_{2}$ e as emissões por unidade de produção são os indicadores mais utilizados pelas empresas. No caso do setor automotivo (tabela 2), esses indicadores são utilizados, respectivamente, por $42 \%$ e $37 \%$ das empresas e no caso do setor de papel e celulose por $70 \%$ e $26 \%$.

Tabela 2

\section{Unidades de medida de GEEs}

\begin{tabular}{|clc|}
\hline Unidade & $\begin{array}{c}\text { Automotivo } \\
(\%)\end{array}$ & $\begin{array}{c}\text { Papel e celulose } \\
(\%)\end{array}$ \\
\hline 1 Não realiza medição de emissões de GEEs & 37 & 30 \\
2 Emissões totais de GEEs & 42 & 70 \\
3 Emissões de GEEs por unidade de produto & 37 & 26 \\
4 Emissões de GEEs por unidade de faturamento & 0 & 0 \\
5 Emissões de GEEs por unidade de produto durante & 0 & 7 \\
O ciclo de vida & 5 & 4 \\
6 Outros & 5 & \\
\hline
\end{tabular}

O impacto que as mudanças climáticas provocam nas empresas as induz a adotar e implantar práticas e estratégias climáticas. Esse impacto é caracterizado na dimensão indutores da variável 2 nas suas principais categorias de construtos, que são: novos mercados, competitividade, fatores intangíveis, fatores financeiros e exposição a riscos.

Vimos que os indicadores para esses construtos variam conforme as particularidades de cada setor e empresa (Hoffman, 2006; Kolk e Pinkse, 2004). Entretanto, alguns desses se aplicam a todos os setores. É o caso da existência de legislações restritivas ao carbono. A pesquisa revelou que as empresas investigadas percebem como indutores mais importantes os seguintes, em or- 
dem decrescente: reputação positiva da empresa e de sua marca; aumento da eficiência operacional da empresa; prática de responsabilidade social; aumento da competitividade junto à concorrência; consistência com a cultura e histórico da empresa; melhoria na gestão de riscos; mudanças na atitude dos consumidores ou clientes. Note que os indutores considerados os mais importantes foram aqueles que obtiveram na pesquisa média acima de 4 .

Lembra-se que de acordo com MDEC, a variável 3 avalia o envolvimento efetivo das empresas na busca da redução de suas emissões de GEEs. Esse envolvimento está caracterizado na dimensão escopo de ação e em seus construtos redução de emissões na empresa, redução de emissões na cadeia de valores expandida, compensação de emissões e acompanhamento de emissões. As questões da variável 3 visam identificar se as empresas instituíram programas de redução de emissões, exploram as transações com créditos de carbono das empresas e procuram conhecer quais ações efetivas as empresas adotam para a redução de suas emissões de GEEs.

Conforme pode ser observado na figura 2 praticamente $3 / 4$ (74\%) das empresas da amostra automotiva ainda não implantaram um programa de redução de emissões de GEEs. Somente cinco das 19 empresas, ou seja 26\%, declararam que implantaram esse tipo de programa. Também é o caso do setor de papel e celulose, em que somente oito das 27 empresas, ou seja, 30\%, declararam que implantaram um programa de redução de emissões.

Figura 2

Implantação de um programa de redução de emissões de GEEs

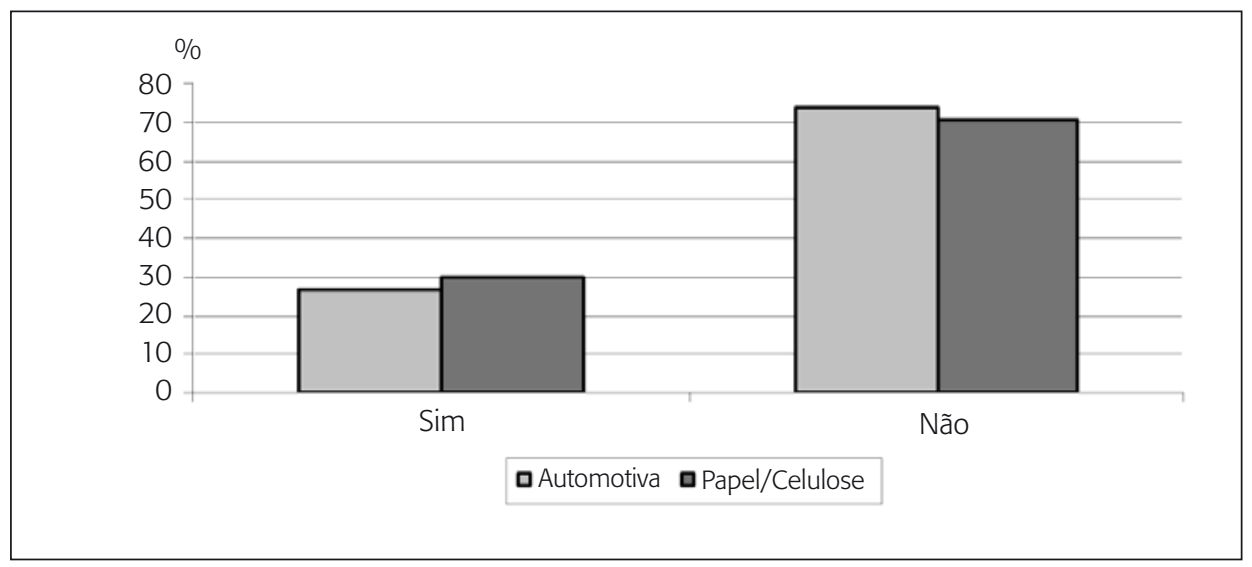

No quadro 7 são apresentados os diferentes tipos de programas implantados para redução de GEEs. Tais programas se dividem em dois grupos. No 
primeiro (coluna esquerda no quadro) encontram-se os programas que efetivamente instituíram metas numéricas de redução de emissões, tanto gerais, quanto por unidade produzida. Na outra coluna constam os programas que se referem à substituição de fontes de energia por fontes menos intensivas em carbono. Observa-se que somente 13 das 46 empresas pesquisadas instituíram programas de redução de GEEs.

\section{Quadro 7}

Programas de redução de GEEs - automotivo e papel e celulose

\begin{tabular}{|c|c|}
\hline Redução & $\begin{array}{l}\text { Utilização de energia menos } \\
\text { intensiva em carbono }\end{array}$ \\
\hline $\begin{array}{l}\text { - Geral de } 1 \% \text { a.a., a partir de baseline de } \\
2003 \text { até } 2006 \\
\text { - Por unidade produzida a partir de } 2007 \\
\text { - Geral de } 25 \% \text { até } 2020 \text { a partir de abril } \\
\text { de } 2008 \\
\text { - Geral de } 5 \% \text {, a partir de } 2006 \text { até } 2010 \\
\text { - Por unidade produzida de } 30 \% \text { com } \\
\text { baseline em } 2000 \\
\text { - Por unidade produzida de } 25 \% \text { das } \\
\text { emissões com baseline em } 2005\end{array}$ & $\begin{array}{l}\text { - Energia neutra em } \mathrm{CO}_{2} \text { a partir de } 2003 \\
\text { Caldeiras a gás natural a partir de março de } 2008 \\
\text { Óleo por gás e redução de emissões a partir de } \\
2004\end{array}$ \\
\hline
\end{tabular}

Todas as empresas da amostra do setor automotivo informaram que não realizavam transações com créditos de carbono em projetos Mecanismos de Desenvolvimento Limpo (MDL), em mercados voluntários ou outros. Já no caso das empresas do setor de papel e celulose pelo menos $40 \%$ das empresas informaram que realizavam transações com créditos de carbono.

Como pode ser visto na tabela 3, as ações mais importantes para redução das emissões de GEE, tanto no setor automotivo quanto no de papel e celulose são: medidas de eficiência energética; gerenciamento ambiental; substituição de combustíveis fósseis; utilização de energia renovável e de material reciclado.

Tabela 3

Indicadores de ações para redução de GEEs

\begin{tabular}{|clcc|}
\hline Indicador & $\begin{array}{c}\text { Automotivo } \\
(\%)\end{array}$ & $\begin{array}{c}\text { Papel e } \\
\text { celulose (\%) }\end{array}$ \\
\hline 1 & Medidas de eficiência energética & 47 & 89 \\
2 & Substituição de combustíveis fósseis & 42 & 70 \\
3 & Análise do ciclo de vida dos produtos & 26 & 19 \\
\hline
\end{tabular}




\begin{tabular}{|clcc|}
\hline Indicador & $\begin{array}{c}\text { Automotivo } \\
(\%)\end{array}$ & $\begin{array}{c}\text { Papel e } \\
\text { celulose (\%) }\end{array}$ \\
\hline 4 Auditoria das emissões na cadeia de suprimentos & 26 & 11 \\
5 & Utilização de energia renovável e de material reciclado & 37 & 78 \\
6 & Parcerias & 21 & 7 \\
7 Comitê executivo & 16 & 22 \\
8 Aferição das emissões próprias por uma terceira parte & 37 & 41 \\
9 & Equipamentos para o monitoramento & 16 & 19 \\
10 & Referencial de excelência para a redução das emissões de GEE & 26 & 19 \\
11 & Gerenciamento ambiental & 84 & 81 \\
\hline
\end{tabular}

A pesquisa revelou que a motivação das empresas (variável 4) para a implantação e execução de estratégias climáticas é bastante semelhante nos dois setores. Lembra-se que os construtos mobilização e divulgação incluem indicadores para medir a motivação para a implantação e o desenvolvimento de uma estratégia climática.

Os dois fatores de motivação mais importantes (com média acima de 4 de acordo com as práticas internacionais), no caso do setor automotivo, são a participação direta da alta administração e a participação direta dos empregados (tabela 4).

Já no caso do setor de papel e celulose, os fatores de motivação mais importantes são a participação direta da alta administração e a comunicação do CEO sobre o posicionamento da empresa quanto às mudanças climáticas. Para os demais itens, nos dois setores, não é atribuída importância significativa. $\mathrm{O}$ recebimento de bônus financeiro associado a metas climáticas foi percebido como o fator de menor importância.

Tabela 4

Fatores de motivação para a implantação de estratégia climática

\begin{tabular}{|clcc|}
\hline Fator & Automotivo & Papel e celulose \\
\hline 1 & Participação direta da alta administração & 4,53 & 4,48 \\
2 & Participação direta dos empregados & 4,16 & 3,89 \\
3 & Autonomia dos empregados & 3,37 & 3,59 \\
4 & Bônus financeiro associado ao atingimento de metas & 2,79 & 3,26 \\
5 & Programa de conscientização dos empregados & 3,79 & 3,81 \\
6 & Programa de treinamento dos empregados & 3,47 & 3,85 \\
7 & Envolvimento de várias áreas da empresa & 3,74 & 4,00 \\
8 Comunicação do CEO sobre o posicionamento da empresa & 3,89 & 4,22 \\
9 & Divulgação interna relativa às mudanças climáticas & 3,53 & 3,85 \\
\hline
\end{tabular}


O construto obstáculos dispõe de indicadores que representam as dificuldades encontradas no âmbito da empresa para o desenvolvimento e implantação da estratégia climática. Conforme exposto na tabela 5 , todos os itens apresentam média superior a dois, o que significa que os obstáculos nas empresas pesquisadas não são reduzidos no mesmo grau que no caso das práticas internacionais. No setor automotivo, o maior obstáculo identificado na pesquisa, para a criação de um clima de motivação, é a carência financeira para o desenvolvimento e implantação de estratégias referentes ao clima. Já no setor de papel e celulose, o maior obstáculo é a carência de competências necessárias ao trato de questões relativas às mudanças climáticas.

Tabela 5

Obstáculos para a criação de um clima de motivação na empresa

\begin{tabular}{|clcc|}
\hline Obstáculo & Automotivo & Papel e celulose \\
\hline 1 Existência na empresa de fontes de resistência & 2,68 & 2,74 \\
2 Carência de competências & 3,11 & 3,41 \\
3 Carência financeira & 3,37 & 3,30 \\
4 Carência de informações & 3,11 & 2,85 \\
\hline
\end{tabular}

No modelo proposto, as relações externas das empresas são consideradas fundamentais para o êxito das estratégias climáticas. Dizem respeito à variável 5 . O construto parcerias e seus respectivos indicadores bem como o construto divulgação e seus respectivos indicadores, compõem esta variável. Como pode ser observado no quadro 13, o item de maior importância para o setor automotivo no que diz respeito às relações externas é a parceria com governos em projetos e programas climáticos. Os itens parcerias com outras empresas em projetos/programas climáticos e parcerias com investidores em projetos/programas climáticos são os de maior importância para o setor de papel e celulose. O item de importância menor, no caso de ambos os setores, são as parcerias com ONGs. No entanto, as médias estão muito próximas para os cinco itens e as frequências bastante concentradas no ponto três da escala de importância, indicando que o relacionamento externo não é reconhecido como um item muito significativo para o êxito das estratégias climáticas, diferentemente das práticas benchmark internacionais. 
Tabela 6

Formas de incrementar o relacionamento externo

\begin{tabular}{|clcc|}
\hline Forma & Automotivo & Papel e celulose \\
\hline 1 & Parcerias com outras empresas & 3,11 & 3,78 \\
2 & Parcerias com ONGs & 2,89 & 3,32 \\
3 & Parcerias com governos & 3,21 & 3,48 \\
4 & Parcerias com associações de classe & 3,16 & 3,33 \\
5 & Parcerias com investidores & 3,16 & 3,85 \\
\hline
\end{tabular}

Também, investigaram-se as formas de divulgação externa das ações climáticas. Como pode ser visto na tabela 7, para ambos os setores, as formas mais importantes de incrementar a divulgação externa das ações climáticas são o relatório anual de atividades e o comunicado do CEO acerca das estratégias e programas relacionados ao clima. Cabe destacar que a participação no Carbon Disclosure Project (CDP) é o item de menor importância, para os dois setores. Os resultados indicam que a divulgação externa não é considerada muito relevante para o êxito das estratégias climáticas, diferentemente das práticas benchmark internacionais.

Tabela 7

Formas de incrementar a divulgação externa das ações

\begin{tabular}{|clcc|}
\hline Forma & Automotivo & Papel e celulose \\
\hline 1 & Relatórios referentes às estratégias relacionadas ao clima & 3,47 & 3,70 \\
2 & Relatório anual de atividades relacionadas ao clima & 3,58 & 4,00 \\
3 & Comunicado CEO sobre os programas/estratégias & 3,58 & 4,00 \\
4 & Participação no Carbon Disclosure Project (CDP) & 2,63 & 3,41 \\
5 & Divulgação/promoção na mídia das atividades & 3,16 & 3,44 \\
\hline
\end{tabular}

\section{Análise dos resultados}

Os resultados da pesquisa sugeriram fortemente que a maioria das empresas tanto do setor automotivo quanto do setor de papel e celulose ainda não tem uma estratégia climática efetivamente implantada (figura 1). Poucas empresas, entre as pesquisadas, adotaram algumas das práticas climáticas necessárias à implantação dessa estratégia. Isso fica particularmente evidente nos testes das hipóteses da pesquisa, descritos a seguir. 
Para testar a hipótese 1 , inicialmente, foi verificado se o poder de indução de cada um dos indutores é compatível com as práticas internacionais. Para isso, realizou-se o teste t-student, a nível de significância de 1\%, para cada setor separadamente. A tabela 8 apresenta de forma concisa os resultados do teste para os dois setores investigados, mostrando somente os indicadores para os quais existem evidências de se rejeitar a hipótese nula e assumir a hipótese alternativa como verdadeira, ou seja, evidências de que os valores possam ser inferiores às práticas internacionais.

Tabela 8

Resultado do teste $t$

Hipótese $1\left(\mathrm{H}_{0}=4,0 ; \mathrm{H}_{1}<4,0\right)$

\begin{tabular}{|c|c|c|}
\hline Perguntas do questionário & $\begin{array}{c}\text { Teste } t \\
p \text {-value }\end{array}$ & Resultado \\
\hline \multicolumn{3}{|l|}{ Automotivo } \\
\hline - Q10_v22 - pressão de ONGs & 0,00048 & \multirow{5}{*}{ Há evidência para rejeitar $\mathrm{H}_{0}$ a $\alpha=0,01$} \\
\hline - Q10_v23 - ocorrência de litígio & 0,00026 & \\
\hline Papel e celulose & & \\
\hline - Q10_v22 - pressão de ONGs & 0,00000 & \\
\hline - Q10_v23 - ocorrência de litígio & 0,00565 & \\
\hline
\end{tabular}

Analisando-se os dados do quadro pode-se concluir que, de um modo geral, o poder de indução dos fatores indutores das estratégias climáticas dos setores automotivo e de papel e celulose acompanha as práticas internacionais. Os pontos a serem melhorados dizem respeito a apenas dois indutores — "pressão das ONGs" e "ocorrências de litígio" — os quais apresentaram na pesquisa poder de indução inferior às práticas internacionais, com resultados estatisticamente significantes ( $p$-value $<1 \%$ ).

O resultado relativo a cada um dos indutores, à exceção dos dois indutores estatisticamente significantes acima mencionados, converge com os estudos de Hoffman (2006), Esty e Winston (2006) quanto à força dos indutores.

No que tange a verificar a similaridade do poder dos indutores na comparação do setor automotivo com o setor de papel e celulose, utilizou-se o teste Kruskal-Wallis, com nível de significância de 1\% para testar a hipótese de que várias populações têm a mesma distribuição em relação às suas variâncias. Nesse caso, ter a mesma distribuição significa que tanto no setor automotivo, quanto no de papel e celulose, os indutores das estratégias climáticas têm, na média, poder de indução semelhante. Somente a variável referente ao 
indicador "possibilidade de geração de crédito de carbono" apresentou diferença entre as médias do setor automotivo e do setor de papel e celulose, pois era estatisticamente significante ( $p$-value $<1 \%$ ).

Seguindo o método adotado no caso do teste da primeira hipótese, a hipótese 2 apresentou evidências para se rejeitar a hipótese nula somente nos casos da "autonomia dos empregados" e do "pagamento de bônus financeiro associado às metas climáticas" (tabela 9). Em outras palavras, somente esses dois mecanismos de criação de um clima de motivação são contemplados pelas empresas em grau de importância inferior às práticas internacionais e constituem, portanto, pontos a serem melhorados pelas empresas nos setores pesquisados.

Tabela 9

Resultado do teste $t$

Hipótese $2\left(H_{0}=4,0 ; H_{1}<4,0\right)$

\begin{tabular}{|lcl|}
\hline Perguntas do questionário & $\begin{array}{c}\text { Teste } t \\
p \text {-value }\end{array}$ & \multicolumn{1}{c|}{ Resultado } \\
\hline Automotivo & & \\
- Q11_v03 - autonomia dos empregados em & 0,00992 & \\
questões referentes às mudanças climáticas & & \\
- Q11_v04 - bônus financeiro associado ao & 0,00030 & \\
atingimento de metas climáticas & & Há evidência para rejeitar \\
Papel e celulose & & $\mathrm{H}_{0}$ a $\alpha=0,01$ \\
- Q11_v03 - autonomia dos empregados em & 0,00879 & \\
$\begin{array}{l}\text { questões referentes às mudanças climáticas } \\
\text { - Q11_v04 - bônus financeiro associado ao } \\
\text { atingimento de metas climáticas }\end{array}$ & 0,00954 & \\
\hline
\end{tabular}

No que concerne à comparação entre os dois setores não há, na média, diferença quanto ao grau de utilização dos mecanismos motivadores, pois, em todos os casos o $p$-value é superior a $1 \%$.

Assim, pode-se inferir que os mecanismos favoráveis à criação de um clima de motivação para a implantação das futuras estratégias climáticas adotadas pelas empresas dos setores de papel e celulose e automotivo, seriam utilizados no mesmo grau das práticas internacionais, à exceção da "autonomia dos funcionários" e do "pagamento de bônus associado a metas climáticas".

Quanto à hipótese 3, a pesquisa revelou que a "carência de competências necessárias ao trato de questões referentes às mudanças climáticas", a "carência financeira para o desenvolvimento e implantação de estratégias cli- 
máticas", além da "carência de informações que indiquem a contribuição das atividades e processos produtivos para as mudanças climáticas", são obstáculos que ainda não são atenuados no mesmo grau das práticas internacionais $(p$-value $<1 \%$ ) (tabela 10).

Tabela 10

Resultado do teste $t$

Hipótese $3\left(\mathrm{H}_{0}=2,0 ; \mathrm{H}_{1}>2,0\right)$

\begin{tabular}{|c|c|c|}
\hline Perguntas do questionário & $\begin{array}{l}\text { Teste } t \\
p \text {-value }\end{array}$ & Resultado \\
\hline \multicolumn{3}{|l|}{ Automotivo } \\
\hline $\begin{array}{l}\text { - Q12_v02 - carência de competências necessárias ao } \\
\text { trato de questões relativas às mudanças climáticas }\end{array}$ & 0,00148 & \\
\hline $\begin{array}{l}\text { - Q12_v03 - carência financeira para o desenvolvimento/ } \\
\text { implantação de estratégias referentes ao clima }\end{array}$ & 0,00007 & \\
\hline $\begin{array}{l}\text { - Q12_v04 - carência de informações que indiquem a } \\
\text { contribuição das atividades/processos produtivos para as } \\
\text { mudanças climáticas devido às suas emissões de GEE }\end{array}$ & 0,00110 & \\
\hline Papel e celulose & & Há evidência para \\
\hline $\begin{array}{l}\text { Q12_v01 - existência na empresa de fontes de } \\
\text { resistência a assuntos ligados às mudanças climáticas }\end{array}$ & 0,00511 & rejeitar $\mathrm{H}_{0}$ a $\alpha=0,01$ \\
\hline $\begin{array}{l}\text { - Q12_v02 - carência de competências necessárias ao } \\
\text { trato de questões relativas às mudanças climáticas }\end{array}$ & 0,00000 & \\
\hline $\begin{array}{l}\text { - Q12_v03 - carência financeira para o desenvolvimento/ } \\
\text { implantação de estratégias referentes ao clima }\end{array}$ & 0,00005 & \\
\hline $\begin{array}{l}\text { Q12_v04 - carência de informações que indiquem a } \\
\text { contribuição das atividades/processos produtivos para as } \\
\text { mudanças climáticas devido às suas emissões de GEEs }\end{array}$ & 0,00410 & \\
\hline
\end{tabular}

Ao comparar os dois setores verificou-se que não há, na média, diferença quanto ao grau de mitigação dos obstáculos em questão, pois em todos os casos o p-value é superior a 1\%. Em ambos os setores os obstáculos não são atenuados suficientemente, diferentemente das práticas benchmark internacionais.

Esses resultados sugerem que no caso das empresas dos setores automotivo e de papel e celulose no Brasil ainda existem obstáculos significativos à criação de um clima de motivação que facilite o trato de questões referentes às mudanças climáticas.

Quanto à hipótese 4, os resultados mais pertinentes são apresentados na tabela 11. Nele, fica evidente que no caso do setor automotivo as "parcerias com outras empresas, como ONGs, associações de classe e investidores 
em projetos/programas climáticos", não são incentivadas suficientemente. Os graus de importância são inferiores às práticas internacionais, uma vez que o p-value é menor do que $1 \%$ para todos os indicadores. No caso do setor de papel e celulose, a importância dada às parcerias como forma de incrementar o relacionamento externo também é inferior às práticas internacionais.

Tabela 11

Resultado do teste $t$

Hipótese $4\left(H_{0}=4,0 ; H_{1}<4,0\right)$

\begin{tabular}{|lll|}
\hline & $\begin{array}{c}\text { Teste } t \\
\text { Pergalue }\end{array}$ & Resultado \\
\hline Automotivo & & \\
- Q13_v1 - parcerias com outras empresas em projetos & 0,00325 & \\
e programas climáticos & & \\
- Q13_v2 - parcerias com ONGs em projetos/programas & 0,00110 & \\
climáticos & & \\
- Q13_v4 - parcerias com associações de classe em & 0,00122 & \\
projetos/programas climáticos & & \\
- Q13_v5 - parcerias com investidores em projetos/ & 0,00197 & Há evidência para rejeitar \\
programas & & Ho $\alpha=0,01$ \\
Papel e celulose & & \\
- Q13_v2 - parcerias com ONGs em projetos/programas & 0,00255 & \\
climáticos & & \\
- Q13_v3 - parcerias com governos em projetos/ & 0,00784 & \\
programas climáticos & & \\
- Q13_v4 - parcerias com associações de classe em & 0,00053 & \\
projetos/programas climáticos & & \\
\hline
\end{tabular}

Como mencionado, os resultados indicam que as empresas do setor de papel e celulose e as do setor automotivo no Brasil ainda não dão a devida importância às parcerias como elemento crítico para o êxito das estratégias climáticas. Assim, diferem completamente das empresas americanas e canadenses que dão grande importância à cooperação entre empresas (Kolk e Pinkse, 2007).

Quanto à comparação entre os dois setores não há, na média, diferença quanto ao grau de utilização das parcerias como forma de incrementar o relacionamento externo, fundamental para o êxito das estratégias climáticas ( $p$-value $>1 \%)$. Em praticamente todos os casos as parcerias não são suficientemente incentivadas. As exceções são a parceria em projetos e programas climáticos com outras empresas, percebida como significativa, no caso do setor 
de papel e celulose, e as parcerias com o governo, percebidas como positivas, no setor automotivo.

No que tange às ações das empresas com vistas à redução de suas emissões de GEEs, a pesquisa revelou que algumas se aplicam a todos os setores e outras, como era de se esperar, variam com as particularidades do segmento e da empresa. Entre as ações universais que se aplicam a qualquer empresa, verificou-se que ainda havia espaço para adotar medidas relativas ao estabelecimento de metas de redução de emissões próprias de GEEs, à eficiência energética, à transformação de resíduos do processo produtivo em coprodutos, à utilização de material reciclado como insumo para a produção, à utilização de energia renovável, à substituição de combustíveis fósseis, à utilização de energia renovável, à comercialização de créditos de carbono oriundos de projetos no âmbito do MDL, à reciclagem de materiais, à análise do ciclo de vida dos produtos (LCA), à auditoria de emissões na cadeia de suprimentos, às parcerias com empresas, ONGs e governo, ao estabelecimento de comitês executivos para as mudanças climáticas, ao acompanhamento e aferição das emissões por uma terceira parte, à instalação de equipamentos para o monitoramento de emissões próprias de GEEs e à instituição de práticas internacionais de redução de emissões.

A pesquisa também revelou que o clima de motivação nas empresas, indispensável ao êxito das estratégias climáticas, ainda não era suficientemente valorizado pelos executivos dos dois setores industriais investigados, se compararmos com as práticas internacionais, especialmente no que se refere à autonomia dos empregados em questões referentes às mudanças climáticas e ao pagamento de bônus financeiro associado a metas climáticas. Ainda, quanto ao clima de motivação, vimos que os obstáculos à criação desse clima não eram mitigados em grau compatível com o das práticas internacionais.

Com relação à hipótese 5 , conforme pode ser visto na tabela 12 , a pesquisa revelou que, no setor automotivo, a participação no Carbon Disclosure Project (CDP) e o uso da mídia para divulgação e promoção das atividades da empresa em prol das mudanças climáticas tinham p-value inferiores a $1 \%$. Esse resultado sugere que na percepção dos executivos esses dois mecanismos não acompanham as práticas internacionais. No caso do setor de papel e celulose, somente o uso da mídia não é considerado em grau compatível com as práticas internacionais ( $p$-value $<1 \%$ ). 
Tabela 12

Resultado do teste $t$

Hipótese $5\left(H_{0}=4,0 ; H_{1}<4,0\right)$

\begin{tabular}{|lll|}
\hline Perguntas do questionário & $\begin{array}{c}\text { Teste } t \\
p \text {-value }\end{array}$ & \multicolumn{1}{c|}{ Resultado } \\
\hline Automotivo & & \\
- Q14_v4 - participação no CDP & 0,00001 & \\
- Q14_v5 - uso da mídia para divulgação/promoção & 0,00294 & \\
de suas atividades em prol do arrefecimento das & & Há evidência para rejeitar Ho \\
mudanças climáticas & a $\alpha=0,01$ \\
Papel e celulose & \\
- Q14_v5 - uso da mídia para divulgação/promoção & 0,00860 & \\
de suas atividades em prol do arrefecimento das & & \\
mudanças climáticas & & \\
\hline
\end{tabular}

A pesquisa revelou que, em comparação com as líderes internacionais, as empresas pesquisadas no Brasil ainda não dão a mesma importância à transparência de informações para os investidores institucionais sobre a situação das empresas diante do risco climático (veja Lash e Wellington, 2007). No caso das empresas investigadas no Brasil, a divulgação e promoção das atividades por meio da mídia não são consideradas vitais para o êxito das estratégias climáticas, contrariamente aos benchmarks pertinentes internacionais. Quanto à comparação entre os dois setores, na média, a pesquisa não encontrou diferença no que concerne ao grau de importância dos mecanismos favoráveis à divulgação externa, pois em todos os casos o $p$-value era superior a $1 \%$.

As consequências de uma divulgação externa ineficiente podem ser bastante negativas. De fato, a falta de uma comunicação externa eficaz e ampla pode reduzir a credibilidade da empresa. Também pode comprometer seus esforços para se diferenciar dos seus concorrentes e para adotar mecanismos de governança climática que promovam a transparência de suas ações junto ao público, investidores, governo e demais stakeholders. Além disso, pode não credenciá-la a participar de ações e programas governamentais de formulação de legislações restritivas ao carbono.

\section{Conclusão}

\section{Considerações gerais}

O artigo apresentou uma ferramenta conceitual, precisamente um Modelo de Estratégias Climáticas (MDEC), baseado em benchmarks internacionais para 
auxiliar na avaliação de práticas e estratégias climáticas e eventualmente, também, na formulação desse tipo de estratégia. Mostrou que esse modelo pode ser aplicado como instrumento de avaliação das práticas e estratégias climáticas nas empresas.

Não obstante a importância das implicações das mudanças climáticas sobre o futuro dos negócios e os paradigmas de produção e consumo de nossa civilização, bem como a exposição contínua do tema na mídia, há uma carência de estudos empíricos sobre o tema, sobretudo sob a ótica da estratégia empresarial. Ou seja, faltam estudos sobre como avaliar e implantar, nas empresas no Brasil, práticas e estratégias climáticas adequadas para explorar as oportunidades e atenuar os riscos e as consequências adversas provenientes das mudanças climáticas.

O modelo proposto buscou contribuir para preencher essa lacuna. De fato, o MDEC contempla, em suas cinco variáveis, as principais características das estratégias climáticas de empresas internacionais líderes na área. Seus construtos e indicadores, inspirados em práticas benchmarks, serviram de base na construção de um questionário para levantar as percepções e outras informações necessárias para sua utilização como ferramenta de avaliação.

Além de ilustrar como aplicar o MDEC, o artigo retratou a realidade das práticas e estratégias climáticas das empresas em dois setores particularmente representativos da economia brasileira inclusive como atores responsáveis pelas consequências das mudanças climáticas - o automotivo e o de papel e celulose. Deixou claro que muitas das empresas nesses setores sequer realizam inventários de suas emissões de $\mathrm{CO}_{2}$ - diretas e indiretas - em linha com os resultados da pesquisa de Enkvist e Vanthournout (2008) sobre as práticas climáticas de 2.193 empresas no mundo. Também em acordo com os últimos autores, revelou que mais da metade das empresas nesses setores no Brasil ainda não têm um programa de redução de emissões, com baseline, metas e prazos definidos devidamente implantado, fundamental para acompanhamento e ajustes nas estratégias climáticas. Evidenciou que as unidades relativas de medidas de GEEs e a adoção de práticas internacionais para comparação não são considerados itens de importância nas estratégias climáticas das empresas nos dois setores focados.

No que se refere à comparação entre os dois setores, o artigo evidenciou que os executivos não atribuem diferenças significativas no grau de importância dos indutores de estratégias climáticas, apesar de as políticas de clima demonstrarem diferenças por setor e localidade, em linha com os estudos de Kolk e Pinkse (2005). 
Acredita-se que a percepção do grau de indução da ocorrência de litígio, inferior às práticas internacionais, nos dois setores pesquisados, esteja relacionado ao fato de que no Brasil ainda não existe uma legislação restritiva aos gases de efeito estufa que embasaria o ajuizamento de ações na justiça. Com o advento de uma legislação restritiva ao carbono que afete todos os negócios e a falta de confiança crescente dos stakeholders, principalmente dos consumidores (Bonini, Hintz e Mendonça, 2008), é muito provável que os principais indutores das estratégias climáticas de cada setor despontem de forma significativa.

\section{Recomendações para futuras pesquisas}

Com relação a futuras pesquisas, a principal recomendação diz respeito à aplicação do modelo proposto a outros setores no Brasil, não somente como instrumento de avaliação, mas também como instrumento de formulação e desenvolvimento de estratégias climáticas. Por enquanto, o MDEC foi aplicado apenas como instrumento de avaliação destas estratégias nas empresas dos setores selecionados.

Sugere-se aprofundar a pesquisa nesse sentido à luz do desafio de assegurar uma adequação estratégica dinâmica, considerando as mudanças constantes ambientais, as climáticas e a dinâmica das suas implicações em todos os níveis, especialmente global.

\section{Recomendações para as empresas}

Para as empresas preocupadas com o impacto crescente das mudanças climáticas em suas operações na busca de vantagens competitivas sustentáveis, são apresentadas sugestões para reflexão.

Uma maneira simples das empresas começarem a aprimorar a eficiência energética interna é reduzindo o consumo de combustíveis fósseis (Enkvist, Nauclér e Oppenheim, 2008). Dada a importância de se ter fotografia inicial dos impactos direto e indireto causados pelas emissões de GEEs, sugere-se que, em todos os casos, as empresas realizem inventários de suas emissões diretas e indiretas como ponto de partida para subsidiar a elaboração de suas estratégias climáticas. Esses inventários, além de fundamentais para a identificação e priorização das opções de redução de emissões de GEEs no âmbito da empresa e de sua cadeia de valores, auxiliam na identificação dos produtos 
e serviços que são mais afetados pelas mudanças climáticas e, também, no conhecimento dos impactos ao longo da cadeia de suprimentos da empresa.

No caso do setor automotivo, as emissões indiretas são responsáveis por um importante impacto climático decorrente da utilização dos veículos ao longo de suas vidas úteis pelo consumidor final. Para esse tipo de setor, sugere-se um aprofundamento da análise do ciclo de vida dos produtos, a fim de incrementar substancialmente as opções de redução das emissões de GEEs.

Recomendam-se também a implantação e o acompanhamento de programas detalhados de redução de emissões, bem como uma auditoria desses programas por uma terceira parte para conferir maior credibilidade e transparência aos resultados.

Sugere-se que as empresas considerem prioritários os fatores de motivação que assegurem o efetivo envolvimento e conscientização de todos os empregados da empresa, propiciando condições de autonomia na busca de soluções aos problemas climáticos e oferecendo programas de recompensas atrelados às metas de redução de emissões. No que diz respeito aos obstáculos, cabe envidar todos os esforços por meio dos mecanismos mitigadores indicados no modelo proposto.

Por fim, recomenda-se que as empresas deem maior atenção às suas relações externas, estabelecendo parcerias pertinentes com terceiros e estimulando a divulgação externa das suas ações em face das mudanças climáticas.

\section{Referências}

ANDERSON, D.; SWEENEY, D.; WILLIAMS, T. Estatística aplicada à administração e economia. São Paulo: Pioneira Thomson Learning, 2005.

BONINI, S. M. J.; HINTZ, G.; MENDONCA, L. T. Addressing consumer concerns about climate change. McKinsey Quarterly, n. 2, p. 52-61, 2008.

CDP (Carbon Disclosure Project). Disponível em: <www.cdproject.net/>.

CERES (Centre for Education and Research in Environmental Strategies). Disponível em: <www.ceres.org.au/>. Acesso em: 20 jun. 2008.

COLLINS, J. Climate change: an environmental and business issue. Business \& Economic Review, v. 53, n. 1, p. 3-10, Oct./Dec. 2006.

ENKVIST, P.; NAUCLÉR, T.; OPPENHEIM, J. M. Business strategies for climate change. McKinsey Quarterly, n. 2, p. 24-33, 2008. 
; VANTHOURNOUT, H. How companies think about climate change. Preview McKinsey Quarterly, v. 8, n. 2, p. 46-51, 2008.

ESTY, D.; WINSTON, A. Green to gold. New Haven and London: Yale University Press, 2006.

HOFER, C.; SCHENDEL, D. Strategy formulation. Analytical concepts. St. Paul: West Publishing Company, 1978.

HOFFMAN, A. J. Competitive environmental strategy: a guide to the changing business landscape. New York: Island Press, 2000.

. Climate change strategy: the business logic behind voluntary greenhouse gas reductions. California Management Review, v. 47, n. 3, 2005.

. Getting ahead of the curve: corporate strategies that address climate change. Prepared for the Pew Center on Global Climate Change. The University of Michigan, 2006.

. Carbon strategies: how leading companies are reducing their climate change footprint. Michigan: The University of Michigan Press, 2007.

IPCC (Intergovernmental Panel on Climate Change). Diversos documentos. Disponível em: <www.ipcc.ch>. Acesso em: 10 dez. 2006.

. Climate change 2007: the physical science basis - summary for policymakers. Geneva: IPCC Secretariat, 2007.

KERLINGER, F. Metodologia da pesquisa em ciências sociais: um tratamento conceitual. São Paulo: Universidade de São Paulo, 1980.

KOLK, A.; PINKSE, J. Market strategies for climate change. European Management Journal, v. 22, n. 3, p. 304-314, 2004.

. Business responses to climate change: identifying emergent strategies. California Management Review, v. 47, n. 3, 2005.

. Multinationals' political activities on climate change. Business Society, v. 46, n. 2, p. 201-228, 2007.

LASH, J.; WELLINGTON, F. Competitive advantage on a warming planet. Harvard Business Review, v. 85, n. 3, p. 94-102, Mar. 2007.

LIS $\varnothing, K$. R. Integrated approach to risk management of future climate change impacts. Building Research \& Information, v. 34, n. 1, p. 1-10, 2006.

MAYNARD, T. Climate change: impacts on insurers and how they can help with adaptation and mitigation. The Geneva Papers, v. 33, p. 140-146, 2008. 
McCLAVE, J. T.; BENSON, P. G.; SINCICH, T. Statistics for business and economics. Upper Saddle River: Prentice Hall, 2001.

PULVER, S. Making sense of corporate environmentalism: an environmental contestation approach to analyzing the causes and consequences of the climate change policy split in the oil industry. Organization Environment, v. 20, n. 1, p. 44-83, 2007.

REA, L. M.; PARKER, R. A. Metodologia de pesquisa: do planejamento à execução. São Paulo: Pioneira, 2000. 